EGU2020-10397

https://doi.org/10.5194/egusphere-egu2020-10397

EGU General Assembly 2020

(c) Author(s) 2020. This work is distributed under

the Creative Commons Attribution 4.0 License.

\title{
Can on-farm irrigation reservoirs enhance long-term sustainability of large irrigated systems? The case of Riegos del Alto Aragón (Spain)
}

David Haro-Monteagudo, Leticia Palazón, and Santiago Beguería

Estación Experimental de Aula Dei, Consejo Superior de Investigaciones Científicas, Av Montañana 1005, 50059, Zaragoza, Spain (dharo@eead.csic.es)

With a total irrigated area above 127,000 ha divided into 58 sectors, the Riegos del Alto Aragón (RAA) irrigation district is currently the largest irrigated area in Spain and in the European Union. Also, it is the largest water user within the Gallego-Cinca subsystem within the Ebro River Basin, which also supplies water to 588 livestock operations, 10 industrial polygons, and 110 populated areas. Although there are plans to increase the irrigated area by another additional 47,000 ha, the system is currently close to its resource limit and several supply restrictions took place in the last years with consequent impacts on agricultural productivity. Moreover, this expansion of the irrigated area collides with environmental objectives in the region, mostly due to water quality and nature conservancy aspects, as well as with other water uses downstream.

The forecasted effects of climate change on future water resources produced in the Pyrenees (the major source of water in the system), as well as market prices, national and international trade and agricultural policies, among other variables, are surrounded by a high level of uncertainty that difficult investment decision-making. Some of the adaptation measures initially devised for the system, e.g. construction of new large reservoirs in the Gallego and Cinca rivers, require either confronting further environmental conflicts or large energy expenses, when not both. With the end of the era of large public works, there is a need to identify new and robust strategies for climate change adaptation. One of these strategies is the construction of private on-farm reservoirs within the RAA system that started in recent years.

The present work evaluates the contribution of on-farm reservoirs to enhancing the long-term sustainability of the RAA system using a multi-model and multi-scenario approach. The Soil and Water Assessment Tool (SWAT) was used to simulate water provisions from the Gallego-Cinca headwater system under an ensemble of downscaled climate models. Afterward, SWAT outputs were fed into a water allocation model built with AQUATOOL to simulate the management of the system's reservoirs, including on-farm reservoirs, and the water supply to the different demands. The performance of agricultural demands and compliance with environmental flow requirements in the system was evaluated for different on-farm reservoir sizes and combined with construction and operational costs to develop sustainability/investment curves. The outcomes have the potential to better inform decision-making from farmers in RAA as well as from managers in the 
Ebro River Basin Agency, providing further understanding of the system's dynamics under climatic change. 